\title{
Competitive interactions among multiple non-native salmonids and two populations of Atlantic salmon
}

\author{
Aimee Lee S. Houde ${ }^{1}$, Chris C. Wilson ${ }^{2}$, Bryan D. Neff ${ }^{1}$ \\ ${ }^{1}$ Department of Biology, Western University, London, ON N6A 5B7, Canada \\ ${ }^{2}$ Aquatic Research and Monitoring Section, Ontario Ministry of Natural Resources, Trent University, Peterborough, ON K9J 7B8, Canada
}

Accepted for publication December 20, 2013

Abstract - Competitive interactions with non-native species can have negative impacts on the conservation of native species, resulting in chronic stress and reduced survival. Here, juvenile Atlantic salmon (Salmo salar) from two allopatric populations (Sebago and LaHave) that are being used for reintroduction into Lake Ontario were placed into semi-natural stream tanks with four non-native salmonid competitors that are established in Ontario streams: brown trout (S. trutta), rainbow trout (Oncorhynchus mykiss), Chinook salmon (O. tshawytscha) and coho salmon (O. kisutch). Brown trout and rainbow trout reduced the survival and fitness-related traits of Atlantic salmon, whereas Chinook salmon and coho salmon had no impact on these traits. These data support theories on ecological niche overlap and link differences in observed aggression levels with competitive outcomes. Measurements of circulating hormones indicated that the Atlantic salmon were not chronically stressed nor had a change in social status at the 10-month time point in the semi-natural stream tanks. Additionally, the Sebago population was better able to coexist with the non-native salmonids than the LaHave population. Certain populations of Atlantic salmon may thus be more suitable for some environments of the juvenile stream phase for the reintroduction into Lake Ontario.

Key words: Ecological niche overlap; aggression; stress; social rank; cortisol; 11-ketotestosterone; survival; life history; reintroduction; restoration; Lake Ontario

\section{Introduction}

Non-native species are one of the leading causes of native species extinctions and declines (Cox 2004; Clavero \& García-Berthou 2005). Non-native species can negatively impact native species by increased predation, competition, parasites, habitat alteration and hybridisation (Gurevitch \& Padilla 2004). For example, introductions of rabbit (Oryctolagus cuniculus) and red foxes (Vulpes vulpes) have caused extinctions of native rodent species in Australia (Smith \& Quin 1996). Similarly, worldwide introductions of brown trout (Salmo trutta) and rainbow trout (Oncorhynchus mykiss) have caused declines in native salmonids (Korsu et al. 2010). In addition, life history traits, such as body size and growth rate, are commonly impacted by non-native species. For example, non- native plants have reduced the biomass of native grasses in North America and Europe (Callaway \& Aschehoug 2000). Similarly, non-native salmonids have reduced the growth and foraging rate of native salmonids (Korsu et al. 2010) and are considered an impediment to rehabilitation of native galaxiid fishes in the Southern Hemisphere (McDowall 2006).

Measures of the endocrine system have also been used to provide insight into the sublethal effects that non-native species can have on native species. Competitive agonistic interactions with non-native species can be a source of chronic stress for native species (Sloman et al. 2001). The endocrine response for dealing with stress is to increase circulating glucocorticoids (Nelson 2011), such as cortisol in fishes (e.g. Wendelaar Bonga 1997; Iwama et al. 2004). An increase in glucocorticoids can be adaptive in the 
short term for acute stressors because of the benefits of increased cardiovascular tone and energy availability (Wendelaar Bonga 1997). However, the increase can be detrimental in the long term for chronic stressors because of the costs of lower disease resistance, growth and reproduction (Pickering \& Pottinger 1989). Losing agonistic interactions can also lead to reduced circulating androgens (Wingfield et al. 1990), such as 11-ketotestosterone in fishes (Oliveira et al. 2009). A decrease in androgens can cause reductions in aggression level and social status that can subsequently lead to lower survival and growth (Huntingford et al. 1990; Nelson 2011).

Salmonid fishes are an important group to examine the effects of introduced or invasive non-native species on native taxa. Several salmonid species have been introduced globally to provide fisheries (Crawford \& Muir 2008), which has created new competitive interactions with ecologically similar native salmonids (Hearn 1987; Fausch 1988). In particular, the juvenile life stages of salmonids are highly competitive periods, as feeding territories are typically limited in nursery streams and individuals aggressively defend those territories (Kalleberg 1958). Survival in juvenile salmonids within nursery streams is often correlated with higher social rank and aggression level, as measured by circulating 11-KT (Oliveira et al. 2009), presumably because these traits are beneficial in acquiring better feeding territories (Fausch 1984; Metcalfe 1986; Ruzzante 1994; Harwood et al. 2003). Individuals with higher social status and aggression level also tend to be larger (Huntingford et al. 1990) and not chronically stressed as measured by circulating cortisol concentrations (Øverli et al. 1999, 2004; Consten et al. 2002).

The presence of non-native salmonids is of particular concern when native species are the focus of conservation efforts. The reintroduction of Atlantic salmon (Salmo salar) to Lake Ontario is a prime example of a native extirpated species whose restoration may be impeded by the presence of four nonnative salmonid species now found in the lakes and tributaries: brown trout, rainbow trout, Chinook salmon (O. tshawytscha) and coho salmon (O. kisutch) (Jones \& Stanfield 1993; Crawford 2001; COSEWIC 2006, 2010). Atlantic salmon were extirpated from Lake Ontario by 1900 (Crawford 2001), and decades of reintroduction attempts have yet to succeed in establishing a self-sustaining population (COSEWIC 2006, 2010). Throughout their evolutionary history, North American populations of Atlantic salmon have not co-occurred with any of these species until recently: although Atlantic salmon and brown trout are broadly sympatric in Europe, North American populations of Atlantic salmon diverged approximately 600,000-700,000 years ago (King et al.
2007). Brown trout and rainbow trout have similar habitat preferences to Atlantic salmon for riffle microhabitats in nursery streams and tend to be more aggressive than Atlantic salmon (e.g. Gibson 1981; Scott et al. 2005). By contrast, Chinook salmon and coho salmon prefer pool microhabitats in nursery streams and exhibit comparable aggression as Atlantic salmon (e.g. Heland \& Beall 1997; Holecek et al. 2009). Based on ecological overlap (Hutchinson 1957) and levels of aggression (Holway \& Suarez 1999), it is thus predicted that competition with brown trout and rainbow trout, rather than with Chinook salmon and coho salmon, may reduce the performance of juvenile Atlantic salmon in streams.

Certain populations of Atlantic salmon may be better able to cope with the increased competition imposed by non-native species. Populations of salmonid species may have genetic differences in behaviour because of differences in their local environments, such as the intensity of predation (Rosenau \& McPhail 1987; Swain \& Holtby 1989; Houde et al. 2010; Van Zwol et al. 2012b). Populations with behaviours, such as increased aggression (Holway \& Suarez 1999) or avoiding agonistic interactions (Metcalfe 1986), may have a better competitive ability. Identifying suitable candidate populations for reintroduction may necessitate experimental approaches examining population performance to important biotic and abiotic features (Meffe 1995), such as the presence of non-native competitors.

Two candidate populations being assessed for reintroduction into Lake Ontario are from Sebago Lake (Sebago) in Maine and from the LaHave River (LaHave) in Nova Scotia (Dimond \& Smitka 2005). These populations were chosen because they each had desirable traits which were identified as priorities for the Lake Ontario rehabilitation effort and because they also vary in their native ecology to increase the potential adaptability to Lake Ontario (Dimond \& Smitka 2005). The Sebago population is native to a landlocked freshwater lake and stocked Sebago-origin Atlantic salmon appear to be doing well in Lake Champlain where they co-exist with stocked and naturalised brown trout and rainbow trout (Marsden et al. 2010). Conversely, the LaHave population, which has been the focus of previous restoration efforts and is able to live in Lake Ontario habitats (Jones \& Stanfield 1993; Greig et al. 2003), is adapted for a large (oceanic) waterbed and has not been exposed to non-native salmonids in its native habitat (Dimond \& Smitka 2005). Here, we examine the survival and fitness-related traits of juvenile Atlantic salmon from these two candidate populations in semi-natural stream tanks with varying extents of competition from juveniles of four non-native salmonid species. Natural stream sites may differ in 


\section{Houde et al.}

environmental variables that can affect the outcome of competition but are not easily controlled, whereas semi-natural streams can control for these variables (see Fausch 1998). Our objective was to test three hypotheses: (i) Atlantic salmon performance in competition with non-native salmonid species will be related to the degree of ecological niche overlap and differences in aggression levels, (ii) juveniles from the two populations will differ in their competitive abilities and performance with non-native salmonids, and (iii) competition with non-native salmonid species will be a source of chronic stress and cause changes in the social status of Atlantic salmon.

\section{Materials and methods}

\section{Study populations and non-native salmonid species}

Juveniles of all salmonid species were provided by the Ontario Ministry of Natural Resources (OMNR). Fertilised eggs from single-pair matings of wild LaHave $\left(44^{\circ} 14^{\prime} \mathrm{N} 64^{\circ} 20^{\prime} \mathrm{W}\right)$ were received from 1989 to 1995 , and captive generations were produced every year in Ontario starting in 1996 (OMNR 2005). Fertilised eggs from single-pair matings of wild Sebago in Panther River $\left(43^{\circ} 53^{\prime} \mathrm{N}, 70^{\circ} 27^{\prime} \mathrm{W}\right)$, a hatchery-supplemented river, were received in 2006. For this study, LaHave and Sebago Atlantic salmon families were produced in early November 2010 using mature individuals at the OMNR Harwood Fish Culture Station, Harwood, Ontario. Five females and five males from each population were mated in all possible combinations to produce a $5 \times 5$ full-factorial breeding design (Lynch \& Walsh 1998). Fertilised eggs and the resultant offspring were reared at the OMNR Codrington Research Facility, Codrington, Ontario. Greater details on the broodstock and rearing of the Atlantic salmon are described in Houde et al. (2013).

Rainbow trout and brown trout were from hatchery parents whose ancestry was derived from naturalised populations of both species in the Ganaraska River, Ontario ( $\left.43^{\circ} 56^{\prime} \mathrm{N} 78^{\circ} 17^{\prime} \mathrm{W}\right)$ (OMNR 2005). Rainbow trout and brown trout families for this experiment were produced by eight single-pair matings at the OMNR Tarentorus Fish Culture Station, Sault Ste. Marie, Ontario, and OMNR Harwood Fish Culture Station respectively. Chinook salmon and coho salmon families were from wild parents from the Credit River $\left(43^{\circ} 33^{\prime} \mathrm{N} 79^{\circ} 34^{\prime} \mathrm{W}\right)$. Chinook salmon and coho salmon families were produced by $30-100$ single-pair matings at the OMNR Normandale Fish Culture Station, Vittoria, Ontario, and OMNR Ringwood Fish Culture Station, Ringwood, Ontario respectively. Random subsets of 250 fry (age $0+$ parr) each for brown trout, rainbow trout, Chinook salmon and coho salmon were transferred from the various OMNR fish culture stations to the OMNR Codrington Research Facility in the spring of 2011. The fry of each species were held in two tanks (38 1, $N=125$ fry) until used in the semi-natural stream tanks. All juveniles were of the same age and culture history as those currently stocked in Lake Ontario streams; thus, fry of these species differed in body size, but were similar to stocking conditions and are therefore representative of the competition in natural streams (see Table 1).

\section{Experimental set-up}

Semi-natural stream tanks were set up at the Codrington Facility. Each tank contained two natural stream microhabitat sections: a riffle section (high velocity, low depth) followed by a pool section (low velocity, high depth) (see Appendices S1-S4). Seven different treatments were set up for juveniles from each Atlantic salmon population, each with a total of 32 juveniles, using a substitutive design to examine the effects of competition (see Fausch 1998). Treatments were as follows: Atlantic salmon alone (LaHave only or Sebago only), Atlantic salmon mixed (LaHave and Sebago together), two species (Atlantic salmon with one of each non-native salmonid species) and multispecies (Atlantic salmon with all four non-native salmonid species) (see Appendices S1-S4). Each treatment was represented by two replicates. In September 2011, fry (age $0+$ parr) of each salmonid

Table 1. Summary of the initial body sizes of fry for LaHave and Sebago Atlantic salmon (Salmo salar) and four non-native salmonid species (brown trout S. trutta; rainbow trout - Oncorhynchus mykiss; Chinook salmon - 0. tshawytscha; and coho salmon - 0. kisutch).

\begin{tabular}{|c|c|c|c|c|c|c|}
\hline \multirow[b]{2}{*}{ Traits } & \multicolumn{2}{|c|}{ Atlantic salmon populations } & \multicolumn{4}{|c|}{ Non-native salmonid species } \\
\hline & LaHave & Sebago & Brown trout & Rainbow trout & Chinook salmon & Coho salmon \\
\hline Length (cm) & $5.8 \pm 0.4^{\mathrm{AD}}$ & $5.6 \pm 0.5^{\mathrm{B}}$ & $6.0 \pm 0.7^{\mathrm{C}}$ & $6.0 \pm 0.6^{\mathrm{CD}}$ & $8.2 \pm 0.7^{\mathrm{E}}$ & $8.5 \pm 1.0^{\mathrm{F}}$ \\
\hline Mass (g) & $2.17 \pm 0.49^{A B}$ & $2.00 \pm 0.51^{\mathrm{A}}$ & $2.43 \pm 0.91^{\mathrm{B}}$ & $2.15 \pm 0.69^{A B}$ & $5.95 \pm 1.74^{\mathrm{E}}$ & $6.68 \pm 2.27^{\mathrm{F}}$ \\
\hline Condition $\left(100 \times \mathrm{g} \cdot \mathrm{cm}^{-3}\right)$ & $1.09 \pm 0.06^{\mathrm{A}}$ & $1.14 \pm 0.06^{\mathrm{B}}$ & $1.05 \pm 0.05^{\mathrm{C}}$ & $0.98 \pm 0.06^{\mathrm{D}}$ & $1.05 \pm 0.10^{C}$ & $1.05 \pm 0.06^{\mathrm{C}}$ \\
\hline
\end{tabular}

Presented are means \pm 1 SD. Different uppercase letters denote homogeneous subsets within populations and species and indicate significant differences assessed using Tukey's post hoc multiple comparisons $(P<0.05)$. Sample sizes are $N=256$ for each Atlantic salmon population and $N=144$ for each non-native salmonid species. 
species were first anaesthetised with tricaine methanesulphonate (MS-222) and tagged by species with visual implant elastomers (Northwest Marine Technology, Washington) at the base of the dorsal and adipose fins (Olsen \& Vøllestad 2001). Random subsets of brown trout, rainbow trout, coho salmon, Chinook salmon and Atlantic salmon fry were selected for the treatments. Fry were measured for fork length (nearest $0.1 \mathrm{~cm}$ ) and mass (nearest $0.01 \mathrm{~g}$ ) before being transferred to the semi-natural stream tanks (see Table 1 and Appendices S1-S4).

The juveniles were kept in the semi-natural stream tanks for 10 months (September to July). Juveniles were subjected to a natural light cycle and fed a competition-inducing ration of $3 \%$ body mass per day (e.g. Garner et al. 2008) of commercial pellets at random times and amounts per day (Keenleyside \& Yamamoto 1962; Symons 1968). The pellets were introduced at the upstream side of the semi-natural stream tanks because in natural streams juvenile salmonids compete for upstream positions to secure the first access to food (Metcalfe 1986). During the winter months, juvenile competition is typically reduced in natural streams because Atlantic salmon seek shelter underneath the substrate and reduce feeding in low water flow areas (Huntingford et al. 1988). Therefore, during the winter months (January to April), the food ration was reduced to $1 \%$ body mass per day.

\section{Survival and fitness-related traits}

Juvenile measurements in the semi-natural stream tanks were collected on October 28, November 29 and July 24, when the juveniles were fed the ration of 3\% body mass per day (i.e. September to December and May to July), but otherwise were left undisturbed (January to April). Juveniles were measured for survival and three fitness-related traits comprising length, mass and condition (Fausch 1984, 1998). We also measured riffle use (the preferred microhabitat of Atlantic salmon) (Morantz et al. 1987). For length, mass and condition, all juveniles were removed from the semi-natural stream tanks, lightly anaesthetised, measured and then allowed to recover before being returned to the semi-natural stream tank. Condition was calculated as $100 \times$ mass.length ${ }^{-3}$ (Fulton 1904). For riffle use, a trained observer took counts of each salmonid species within the riffle section at 12:00 on the day after body size measurements, taking care to limit visual exposure to the juveniles. We also examined riffle use by taking photographs the day before body size measurements, but did not have the data for all measurement dates. We therefore concentrated our analysis on the observer data.
Blood samples and circulating hormone concentrations

At the termination of the experiment, juveniles were starved for $24 \mathrm{~h}$ and then quickly netted out of the semi-natural stream tank until up to eight Atlantic salmon were collected. Care was taken to minimally disturb the juveniles while netting. Atlantic salmon were quickly submerged in an overdose of anaesthetic (MS-222) until gill movement ceased, then immediately measured for length and mass, and blood was collected from the caudal peduncle using a heparin-lined tube. The time from the initial disturbance of the juveniles to blood collection was recorded for each Atlantic salmon. Care was taken to ensure that the entire process took $<5$ min per seminatural stream tank (see Sumpter et al. 1986). Plasma was immediately separated in the blood by centrifugation (1500 $g$ for $5 \mathrm{~min}$ ) and stored at $-20{ }^{\circ} \mathrm{C}$ until analysis (Van Zwol et al. 2012a).

Prior to the enzyme immunoassay for 11-ketotestosterone (11-KT), $10 \mu \mathrm{l}$ plasma samples was extracted three times with $2.5 \mathrm{ml}$ diethylether using a snap-freeze method described by Van der Kraak et al. (1989). The diethylether was evaporated in a fume hood, and then, the samples were stored at $-20{ }^{\circ} \mathrm{C}$ until assayed (Van Zwol et al. 2012a). Plasma concentrations of cortisol and 11-KT were determined using the manufacturer's instructions for enzyme immunoassay kits (Cayman Chemical Company, Ann Arbor, MI, USA). Briefly, 11-KT samples were reconstituted with assay buffer prior to the assay. Each sample was run in triplicate, with $50 \mu \mathrm{l}(1 / 20$ plasma dilution for cortisol and 11-KT) loaded into each well. Plates were read at an absorbance of $405 \mathrm{~nm}$.

\section{Statistical analysis of traits}

Survival, length, mass, condition, riffle use and circulating hormones concentrations of individual Atlantic salmon were analysed in R 2.15.3 (available at http:// www.r-project.org/). Statistical significance was set at $\alpha=0.05$. There were no significant differences between the populations in Atlantic salmon alone (LaHave only or Sebago only) and Atlantic salmon mixed (LaHave and Sebago together) treatments (data not shown); therefore, the juveniles from the mixed treatment were pooled with their appropriate population in the 'alone' treatment for comparisons to other treatments.

Due to the Atlantic salmon mortality over the winter, which led to differences in juvenile densities for May through July (see Appendices S1-S4), individual traits were statistically examined at the 3-month mark (November 29) and again at the 10-month mark (July 24). Data from the 2-month mark (October 28) 


\section{Houde et al.}

are not presented because there were few significant differences between the treatments. The data are available from the authors. Survival and riffle use data were logit-transformed, and circulating hormones concentrations were natural log +1 -transformed to increase normality. Linear models were used to examine effects for survival and riffle use. Linear mixed-effects models (lmer in the lme4 package of $\mathrm{R})$ were used to examine effects for length, mass, condition, cortisol concentrations and 11-KT concentrations of individuals. Atlantic salmon models contained fixed effects for population, treatment and population $\times$ treatment, and mixed-effects models contained a random effect for semi-natural stream tank identity.

\section{Results}

\section{Survival}

Significant treatment and population by treatment effects were detected for the survival of Atlantic salmon (Table 2; Fig. 1; see Appendices S1-S4 for summary of all data). There was no difference between the populations in survival at either time point. The survival of both populations was decreased in the presence of brown trout at 10 months, but not at 3 months. The presence of rainbow trout decreased the survival of LaHave juveniles at 10 months. The multi-species treatment decreased the survival of LaHave juveniles at 3 months, but had the opposite effect for Sebago juveniles at 3 months. However, the multi-species treatment did decrease the survival of both populations at 10 months. The presence of coho salmon increased the survival of Sebago juveniles at 3 months (relative to the alone treatment), but otherwise had no effect. There was no significant effect of the presence of Chinook salmon on the survival for either population at either time.

\section{Length, mass, condition and riffle use}

The two Atlantic salmon populations initially differed in length and condition, but not mass, with LaHave juveniles being longer and lower condition than Sebago juveniles (Table 1). Among the five salmonid species, coho salmon were the largest in initial body

Table 2. Summary of model results for traits in LaHave and Sebago Atlantic salmon (Salmo salar).

\begin{tabular}{|c|c|c|c|c|c|c|}
\hline \multirow[b]{2}{*}{ Trait } & \multicolumn{3}{|c|}{3 months } & \multicolumn{3}{|c|}{10 months } \\
\hline & d.f. & F-statistic & $P$-value & d.f. & F-statistic & $P$-value \\
\hline \multicolumn{7}{|l|}{ Survival } \\
\hline Population & 1,16 & 0.05 & 0.824 & 1,16 & 0.48 & 0.500 \\
\hline Treatment & 5,16 & 1.74 & 0.182 & 5,16 & 18.46 & $<0.001$ \\
\hline Population $\times$ treatment & 5,16 & 4.15 & 0.013 & 5,16 & 2.16 & 0.110 \\
\hline \multicolumn{7}{|l|}{ Length } \\
\hline Population & $1,461.9$ & 5.73 & 0.017 & 1,355 & 1.82 & 0.178 \\
\hline Treatment & $5,461.9$ & 4.02 & 0.001 & 5,355 & 4.71 & $<0.001$ \\
\hline Population $\times$ treatment & $5,461.9$ & 0.46 & 0.808 & 5,355 & 0.71 & 0.617 \\
\hline \multicolumn{7}{|l|}{ Mass } \\
\hline Population & $1,461.9$ & 0.24 & 0.623 & 1,355 & 1.20 & 0.274 \\
\hline Treatment & $5,461.9$ & 6.56 & $<0.001$ & 5,355 & 5.78 & $<0.001$ \\
\hline Population $\times$ treatment & $5,461.9$ & 0.58 & 0.712 & 5,355 & 0.60 & 0.699 \\
\hline \multicolumn{7}{|l|}{ Condition } \\
\hline Population & $1,26.0$ & 53.25 & $<0.001$ & $1,44.1$ & 3.40 & 0.072 \\
\hline Treatment & $5,21.0$ & 8.45 & $<0.001$ & $5,12.2$ & 2.22 & 0.118 \\
\hline Population $\times$ treatment & $5,26.2$ & 1.16 & 0.355 & $5,17.2$ & 2.09 & 0.116 \\
\hline \multicolumn{7}{|l|}{ Riffle use } \\
\hline Population & 1,16 & 0.00 & 0.988 & 1,16 & 0.01 & 0.938 \\
\hline Treatment & 5,16 & 2.87 & 0.049 & 5,16 & 9.29 & $<0.001$ \\
\hline Population $\times$ treatment & 5,16 & 1.75 & 0.181 & 5,16 & 2.75 & 0.030 \\
\hline \multicolumn{7}{|l|}{ Cortisol concentrations } \\
\hline Population & & & & $1,14.1$ & 0.29 & 0.601 \\
\hline Treatment & & & & $5,32.3$ & 3.06 & 0.023 \\
\hline Population $\times$ treatment & & & & $5,28.7$ & 1.21 & 0.330 \\
\hline \multicolumn{7}{|l|}{ 11-KT concentrations ${ }^{\dagger}$} \\
\hline Population & & & & $1,23.9$ & 7.57 & 0.011 \\
\hline Treatment & & & & $5,27.6$ & 0.67 & 0.652 \\
\hline
\end{tabular}

Displayed are linear model results for survival and riffle use and linear mixed-effects results for length, mass, condition, circulating cortisol concentrations and circulating 11-ketotestosterone concentrations (11-KT). Population and treatment were coded as fixed effects in all models, and mixed-effects models contained a random effect for semi-natural stream tank identity.

†Sample size was too small to examine a population $\times$ treatment interaction. 

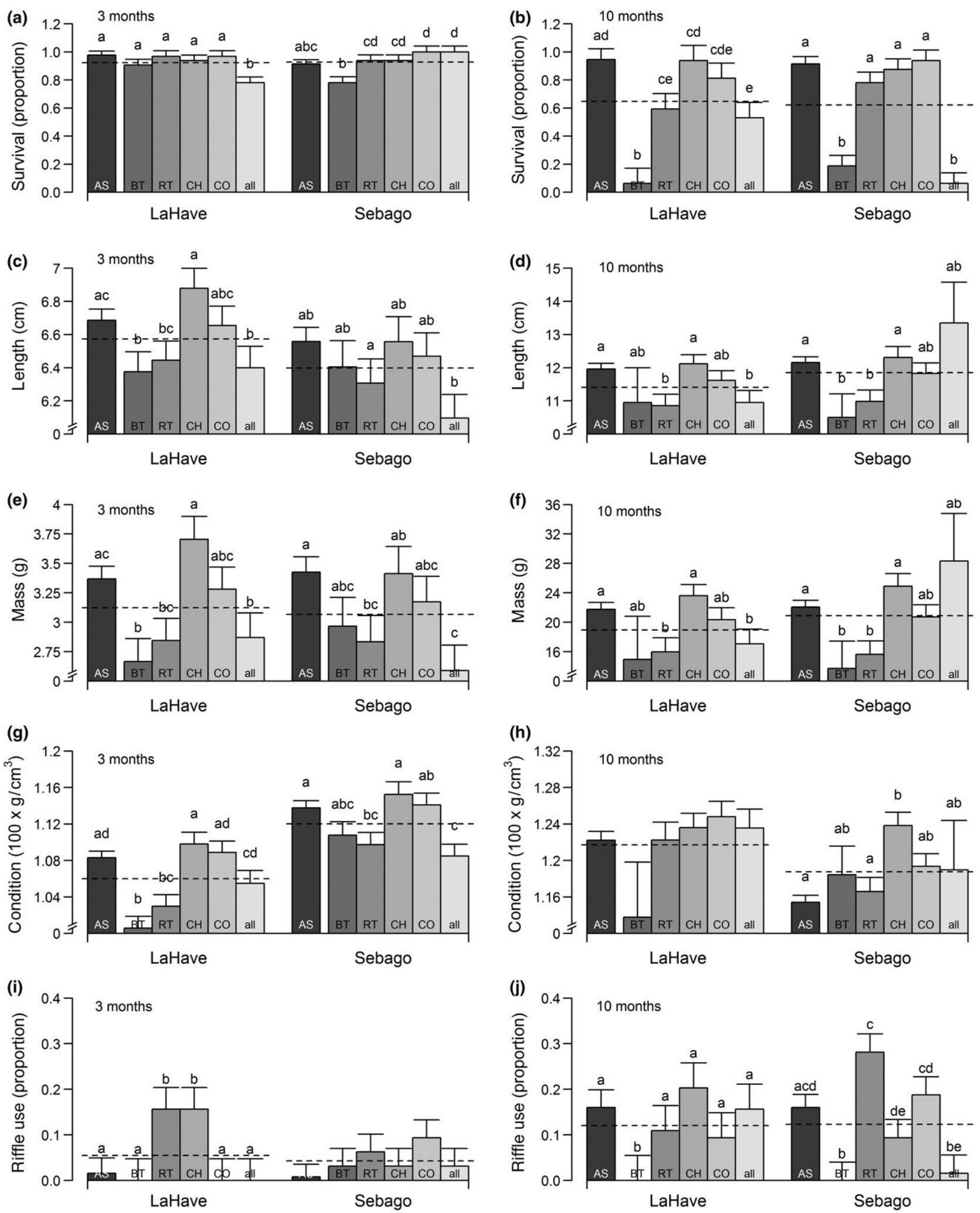

Fig. 1. Traits in the semi-natural stream tanks at 3 and 10 months of LaHave and Sebago Atlantic salmon (Salmo salar). Treatment symbols are $\mathrm{AS}=$ pooled Atlantic salmon alone and Atlantic salmon mixed, BT $=$ Atlantic salmon with brown trout, RT $=$ Atlantic salmon with rainbow trout, $\mathrm{CH}=$ Atlantic salmon with Chinook salmon, $\mathrm{CO}=$ Atlantic salmon with coho salmon, all $=$ Atlantic salmon with all four non-native salmonid species. Displayed are means $\pm 1 \mathrm{SE}$ for treatments. Dashed lines are the means for the population across all treatments. Different lowercase letters denote homogeneous subsets within populations and indicate significant differences assessed using Tukey's post hoc multiple comparisons $(P<0.05)$. 


\section{Houde et al.}

size followed by Chinook salmon, brown trout, rainbow trout and both populations of Atlantic salmon. Initial body condition was similar for coho salmon, Chinook salmon and brown trout, higher for Sebago juveniles and lower for LaHave juveniles and rainbow trout relative to the other species (Table 1).

Significant population and treatment effects were detected for the length, mass and condition of Atlantic salmon at both 3 and 10 months (Table 2; Fig. 1). Sebago juveniles had higher condition than LaHave juveniles at 3 months, but this pattern was reversed at 10 months, although, when alone, there were no differences between the populations in length, mass or condition at either time (one-way ANOvas, $P>0.14$ for all). The presence of brown trout decreased the length and mass of LaHave juveniles, but not Sebago juveniles at 3 months. However, the presence of brown trout did decrease the mass of Sebago juveniles at 10 months. The presence of rainbow trout decreased LaHave juveniles mass and Sebago juveniles condition at 3 months as well as the length and mass of both populations at 10 months. The multi-species treatment decreased the Atlantic salmon length in both populations and the mass and condition of Sebago juveniles at 3 months. The multi-species treatment also decreased the length and mass of LaHave juveniles at 10 months. There were no significant effects of the presence of Chinook salmon and coho salmon on length, mass and condition for either population at either time.

Significant treatment and population by treatment effects were detected for the riffle use of Atlantic salmon at 3 months and 10 months (Table 2; Fig. 1). There was, however, no difference between the populations in riffle use. The presence of brown trout decreased the riffle use of both populations at 10 months, but not at 3 months. The multi-species treatment decreased the riffle use of Sebago juveniles at 10 months, but otherwise had no effect. The presence of rainbow trout and Chinook salmon increased the riffle use of LaHave juveniles at 3 months, but not at 10 months. There was no significant effect of the presence of coho salmon on the riffle use for either population at either time. Similar riffle use results were found when analysing the photograph data at 3 months (data not shown).

\section{Circulating hormone concentrations}

No population differences in circulating cortisol concentrations were detected across all treatments, but significant treatment effects were observed (Table 2; Fig. 2). However, when alone, Sebago juveniles had higher circulating cortisol concentrations than LaHave juveniles $\left(F_{1,25.9}=36.33, P<0.001\right)$. The multi-species treatment increased the circulating
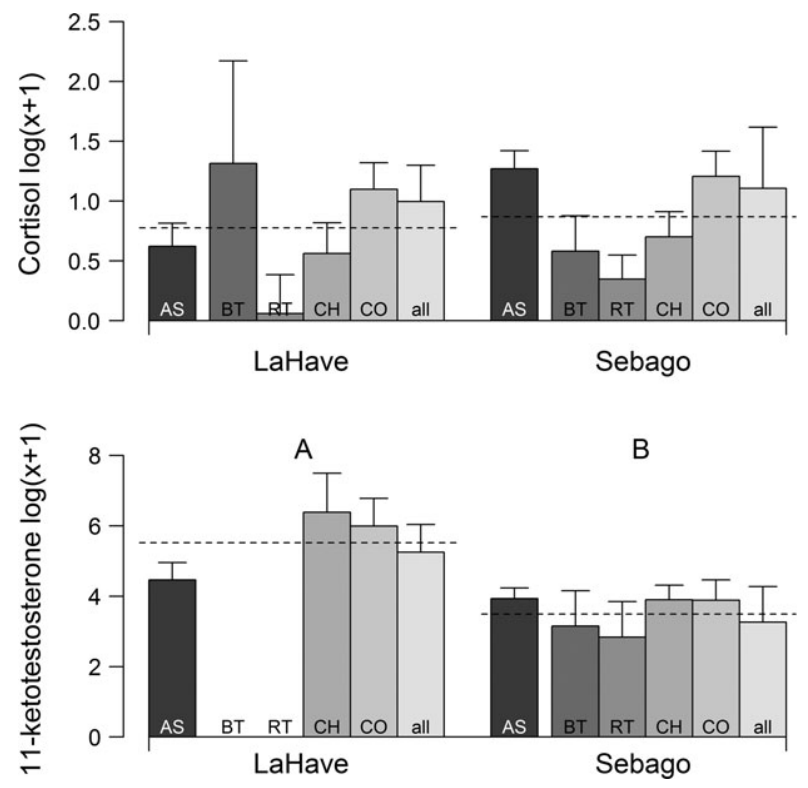

Fig. 2. Circulating hormone concentrations in the semi-natural stream tanks at 10 months of LaHave and Sebago Atlantic salmon (Salmo salar). Circulating cortisol concentration was measured in $\mathrm{ng} \cdot \mathrm{ml}^{-1}$ and circulating 11-ketotestosterone (11-KT) in $\mathrm{pg} \cdot \mathrm{ml}^{-1}$, but are natural $\log +1$-transformed in the analysis. The treatment symbols are the same as those described in the caption for Fig. 1. Different uppercase letters denote homogeneous subsets between populations and indicate significant differences assessed using Tukey's post hoc multiple comparisons $(P<0.05)$. There was insufficient plasma to examine circulating $11-\mathrm{KT}$ concentrations for LaHave juveniles in the brown trout and rainbow trout treatments.

cortisol concentrations of LaHave juveniles, but not Sebago juveniles, whereas the presence of rainbow trout had the opposite effect. There was no significant effect of the presence of brown trout, Chinook salmon and coho salmon on the circulating cortisol concentrations in either population, although the lack of effect detection for the presence of brown trout may have been limited by high variances (Fig. 2).

Significant population effects were detected for circulating 11-KT concentrations (Table 2; Fig. 2). Sebago juveniles had lower circulating 11-KT concentrations than LaHave juveniles across all treatments, but when alone, there was no difference between the populations $\left(F_{1,9}=3.46, P=0.096\right)$. There was no significant effect of the presence of brown trout, rainbow trout, Chinook salmon, coho salmon and the multi-species treatment on circulating 11-KT concentrations.

Length and mass of Sebago juveniles were positively correlated with circulating cortisol concentrations (length: $r=0.362$, d.f. $=66, P=0.002$ and mass: $r=0.345$, d.f. $=66, P=0.004$ ), but length and mass of LaHave juveniles and condition for either population were not $(P>0.64$ for all). There were no correlations between these metrics with 
circulating 11-KT concentrations for either population $(P>0.12$ for all).

\section{Discussion}

The results of our study concur with general findings that the presence of non-native species can reduce the performance of native species, and provide a causal mechanism for reduced juvenile fitness-related traits and survival. We found that Atlantic salmon survival and other fitness-related traits were negatively impacted by competition with non-native brown trout (four of five measured traits), rainbow trout (three of five traits) and in the multi-species treatment (five of five traits). These effects were similar at the 3- and 10-month time points, albeit we cannot rule out density effects for the 10-month time point because of differential mortality across treatments (also see Fausch 1998). On the other hand, Atlantic salmon survival and the fitness-related traits were not reduced when in competition with Chinook salmon or coho salmon (in both cases, zero of five traits were impacted). Chinook salmon and coho salmon have little ecological niche overlap with Atlantic salmon in streams and typically exhibit comparable aggression as Atlantic salmon (Gibson 1981; Beall et al. 1989; Heland \& Beall 1997; Scott et al. 2005; Holecek et al. 2009). In contrast, brown trout and rainbow trout have similar ecological niches as Atlantic salmon in streams and are typically more aggressive than Atlantic salmon (Gibson 1981; Hearn \& Kynard 1986; Volpe et al. 2001; Scott et al. 2005; Vehanen 2006). Our results are similar to natural stream studies that found reduced survival and growth of juvenile Atlantic salmon in the presence of rainbow trout (e.g. Jones \& Stanfield 1993; Stanfield \& Jones 2003; Coghlan et al. 2007), while providing additional insights on stress levels within individual juveniles. Collectively, these data suggest that in tributary habitat, the presence of non-native species with overlapping ecological niches or higher aggression than Atlantic salmon may impede their restoration.

Populations of native species may differ in their competitiveness with non-native species. Although the presence of rainbow trout reduced the body size of both populations at the 10-month time point in our experiment, we found that the presence of rainbow trout reduced the survival of LaHave juveniles, but not Sebago juveniles, suggesting that the Sebago juveniles may be the more fit of the two in streams occupied by rainbow trout. Previous work indicates that populations or species that are better competitors either display higher levels of aggression or are better at avoiding agonistic interactions (Metcalfe 1986; Holway \& Suarez 1999). It is unlikely that Sebago juveniles are more aggressive than LaHave juveniles, as Sebago juveniles did not reduce the survival or any of the fitness-related traits of LaHave juveniles in the 'mixed' experimental treatment where juveniles from both populations were reared together. Differences in fitness-related traits are expected if the individuals differed in aggression levels (e.g. Ruzzante 1994). A previous study by Van Zwol et al. (2012b) showed that Sebago juveniles had fewer agonistic interactions with brown trout and rainbow trout relative to LaHave juveniles, suggesting that avoidance of agonistic interactions may be the behavioural mechanism underlying their competitive differences. Populations of native species that avoid agonistic interactions might therefore fair better when in competition with non-native species and could serve as better targets for breeding programmes during restoration.

Circulating levels of hormones are commonly used in fishes to assess stress and social status. Based on using circulating concentrations of cortisol, we found that competition with non-native species did not appear to affect stress in Atlantic salmon. Specifically, while circulating cortisol concentrations increased for LaHave juveniles in the multi-species treatment, the cortisol concentrations were not at a level indicative of chronic stress in salmonids (i.e. 10 ng. $\mathrm{ml}^{-1}$, Maule et al. 1987; Pickering \& Pottinger 1989). We also found no difference between the treatments in circulating 11-KT concentrations, a hormone used as a measure of social status (Huntingford et al. 1990; Nelson 2011). Some caution is warranted when interpreting the hormone results, however, as the juveniles we sampled were those that survived over the winter. Conceivably, the individuals that died may have been of lower social status and succumbed to chronic stress (see Wendelaar Bonga 1997; Gregory \& Wood 1999). Alternatively, the Atlantic salmon may have acclimatized to the prolonged chronic stress (i.e. after 10 months of competition with non-native salmonid species). Prolonged exposure to a chronic stressor can decrease the production of cortisol (see Wendelaar Bonga 1997). In addition, different life stages tend to have different sensitivities to stressors, with younger juvenile salmonids typically being more tolerant of anthropogenic handling, and possibly agonistic interactions, than older life stages (Wendelaar Bonga 1997). Indeed, Atlantic salmon that were a year older and exposed to a shorter period (8 days) of social interactions with non-native salmonid species had an increase in circulating cortisol concentrations to a level indicative of chronic stress (Van Zwol et al. 2012a).

It is also possible that the circulating hormone concentrations in the Atlantic salmon simply relate to metabolism (Wendelaar Bonga 1997; Mommsen 


\section{Houde et al.}

et al. 1999). Indeed, we found that Sebago juveniles had a significant positive relationship between circulating cortisol concentration and body size. Larger juveniles typically have a higher metabolic rate (Metcalfe et al. 1995), and circulating cortisol concentrations may have increased proportionally to metabolic rate given the food-deprived conditions (i.e. starvation for $24 \mathrm{~h}$ in this study; see Wendelaar Bonga 1997; Mommsen et al. 1999). Other hormones, such as growth hormone (Jonsson et al. 1998), testosterone (Desjardins et al. 2006) and arginine vasotocin (Dewan \& Tricas 2011), may instead be involved in mediating aggression, social status and ultimately stress in juvenile salmonids. These other hormones deserve further attention.

Finally, our results may have implications for candidate population selection in the restoration of extirpated species. The presence of non-native salmonid species may be a significant impediment to Atlantic salmon restoration in Lake Ontario (COSEWIC 2006, 2010). We found that LaHave juveniles had higher survival and condition within the multi-species treatment as compared to Sebago juveniles, whereas Sebago juveniles had higher survival and condition in the presence of either brown trout or rainbow trout. The LaHave population may therefore be an environment match to streams containing all four non-native salmonids species, whereas the Sebago population may be an environment match to streams containing brown trout and rainbow trout only. In addition, combining our analysis with those of Van Zwol et al. (2012a,b), over the entire 2-year stream residency period, brown trout appear to have the greatest impact on the survival and fitness-related traits of juvenile Atlantic salmon and may be a key non-native species impeding the restoration of Atlantic salmon into the Great Lakes. Of course, comparisons of the candidate populations in natural streams and over the entire life cycle, including adult performance in the lake environment, are needed before firm recommendations can be made on candidate population selection. Nevertheless, consideration of candidate populations that are an environment match to important environment features, such as the presence of non-native species, may help to ensure restoration success.

\section{Acknowledgements}

The research was supported by the Natural Sciences and Engineering Research Council of Canada through a postgraduate student research award to ASH and a Strategic Project Grant to BDN. The research was also supported by the Ontario government (Queen Elizabeth II Graduate Scholarship to ASH), Ontario Ministry of Natural Resources (T. Stewart, M. Daniels, D. Rosborough, C. Weaver and A. Kidd), Ontario
Federation of Anglers and Hunters, and Metro East Anglers (A. Rubaszek). W. Sloan, S. Ferguson and B. Lewis provided invaluable support and assistance at the OMNR Codrington Research Facility. We thank H. Dokter, A. Smith, X. He, C. Black, J. Van Zwol, S. Garner, T. Hain, M.-C. Bellmare, M.H. Greffard and H. Allegue for assistance in semi-natural stream tank construction and data collection.

\section{References}

Beall, E., Heland, M. \& Marty, C. 1989. Interspecific relationships between emerging Atlantic salmon, Salmo salar, and coho salmon, Oncorhynchus kisutch, juveniles. Journal of Fish Biology 35: 285-293.

Callaway, R.M. \& Aschehoug, E.T. 2000. Invasive plants versus their new and old neighbors: a mechanism for exotic invasion. Science 290: 521-523.

Clavero, M. \& García-Berthou, E. 2005. Invasive species are a leading cause of animal extinctions. Trends in Ecology and Evolution 20: 110.

Coghlan, S.M. Jr, Connerton, M.J., Ringler, N.H., Stewart, D.J. \& Mead, J.V. 2007. Survival and growth responses of juvenile salmonines stocked in eastern Lake Ontario tributaries. Transactions of the American Fisheries Society 136: 56-71.

Consten, D., Lambert, J.G.D., Komen, H. \& Goos, H.J.T. 2002. Corticosteroids affect the testicular androgen production in male common carp (Cyprinus carpio L.). Biology of Reproduction 66: 106-111.

[COSEWIC] Committee on the Status of Endangered Wildlife in Canada. 2006. COSEWIC assessment and status report on the Atlantic salmon Salmo salar (Lake Ontario population) in Canada. Ottawa: Committee in the Status of Endangered Wildlife in Canada, vii +26 pp.

[COSEWIC] Committee on the Status of Endangered Wildlife in Canada. 2010. COSEWIC assessment and status report on the Atlantic salmon Salmo salar (anadromous form) in Canada. Ottawa: Committee in the Status of Endangered Wildlife in Canada, xlvii +136 pp.

Cox, G.W. 2004. Alien species and evolution: the evolutionary ecology of exotic plants, animals, microbes, and interacting native species. Portland: Book News, 377 pp.

Crawford, S.S. 2001. Salmonine introductions to the Laurentian Great Lakes: an historical review and evaluation of ecological effects. Canadian Special Publication of Fisheries and Aquatic Sciences 132. Ottawa: National Research Council of Canada. 205 pp.

Crawford, S.S. \& Muir, A.M. 2008. Global introductions of salmon and trout in the genus Oncorhynchus: 1870-2007. Reviews in Fish Biology and Fisheries 18: 313-344.

Desjardins, J.K., Hazelden, M.R., Van der Kraak, G.J. \& Balshine, S. 2006. Male and female cooperatively breeding fish provide support for the "Challenge Hypothesis". Behavioral Ecology 17: 149-154.

Dewan, A.K. \& Tricas, T.C. 2011. Arginine vasotocin neuronal phenotypes and their relationship to aggressive behavior in the territorial monogamous multiband butterflyfish, Chaetodon multicinctus. Brain Research 1401: 74-84.

Dimond, P. \& Smitka, J. 2005. Evaluation of selected strains of Atlantic salmon as potential candidates for the restoration 
of Lake Ontario. Trout Unlimited Canada Technical Report ON-012. Guelph: Trout Unlimited Canada. 41 pp.

Fausch, K.D. 1984. Profitable stream positions for salmonids: relating specific growth rate to net energy gain. Canadian Journal of Zoology 62: 441-451.

Fausch, K.D. 1988. Tests of competition between native and introduced salmonids in streams: what have we learned? Canadian Journal of Fisheries and Aquatic Sciences 45: 2238-2246.

Fausch, K.D. 1998. Interspecific competition and juvenile Atlantic salmon (Salmo salar): on testing effects and evaluating the evidence across scales. Canadian Journal of Fisheries and Aquatic Sciences 55: 218-231.

Fulton, T.W. 1904. The rate of growth of fishes. 22nd Annual Report of the Fishery Board of Scotland 1904. Edinburgh: Fisheries Board of Scotland. pp. 141-241.

Garner, S.R., Madison, B.N., Bernier, N.J. \& Neff, B.D. 2008. Juvenile growth and aggression in diploid and triploid Chinook salmon Oncorhynchus tshawytscha (Walbaum). Journal of Fish Biology 73: 169-185.

Gibson, R.J. 1981. Behavioural interactions between coho salmon (Oncorhynchus kisutch), Atlantic salmon (Salmo salar), brook trout (Salvelinus fontinalis) and steelhead trout (Salmo gairdneri) at the juvenile fluviatile stages. Canadian Technical Report of Fisheries and Aquatic Sciences 1029. St. John's: Department of Fisheries and Oceans, 116 pp.

Gregory, T.R. \& Wood, C.M. 1999. The effects of chronic plasma cortisol elevation on the feeding behaviour, growth, competitive ability, and swimming performance of juvenile rainbow trout. Physiological and Biochemical Zoology 72: 286-295.

Greig, L., Ritchie, B., Carl, L. \& Lewis, C.A. 2003. Potential and strategy for restoration of Atlantic Salmon in Lake Ontario: a workshop report. Peterborough: Ontario Ministry of Natural Resources, $39 \mathrm{pp}$.

Gurevitch, J. \& Padilla, D.K. 2004. Are invasive species a major cause of extinctions? Trends in Ecology and Evolution 19: 470-474.

Harwood, A.J., Griffiths, S.W., Metcalfe, N.B. \& Armstrong, J.D. 2003. The relative influence of prior residency and dominance on the early feeding behaviour of juvenile Atlantic salmon. Animal Behaviour 65: 1141-1149.

Hearn, W.E. 1987. Interspecific competition and habitat segregation among stream-dwelling trout and salmon: a review. Fisheries 12: 24-31.

Hearn, W.E. \& Kynard, B.E. 1986. Habitat utilization and behavioral interaction of juvenile Atlantic salmon (Salmo salar) and rainbow trout (S. gairdneri) in tributaries of the White River of Vermont. Canadian Journal of Fisheries and Aquatic Sciences 43: 1988-1998.

Heland, M. \& Beall, E. 1997. Étude expérimentale de la compétition interspécifique entre juvéniles de saumon coho, Oncorhynchus kisutch, et de saumon atlantique, Salmo salar, en eau douce. Bulletin Francais de la Peche et de la Pisciculture 344/345: 241-252.

Holecek, D.E., Cromwell, K.J. \& Kennedy, B.P. 2009. Juvenile Chinook salmon summer microhabitat availability, use, and selection in a central Idaho wilderness stream. Transactions of the American Fisheries Society 138: 633-644.

Holway, D.A. \& Suarez, A.V. 1999. Animal behavior: an essential component of invasion biology. Trends in Ecology and Evolution 14: 328-330.
Houde, A.L.S., Fraser, D.J. \& Hutchings, J.A. 2010. Fitnessrelated consequences of competitive interactions between farmed and wild Atlantic salmon at different proportional representations of wild-farmed hybrids. ICES Journal of Marine Sciences 67: 657-667.

Houde, A.L.S., Wilson, C.C. \& Neff, B.D. 2013. Genetic architecture of survival and fitness-related traits in two populations of Atlantic salmon. Heredity 11: 513-519.

Huntingford, F.A., Metcalfe, N.B. \& Thorpe, J.E. 1988. Choice of feeding station in Atlantic salmon, Salmo salar, parr: effects of predation risk, season and life history strategy. Journal of Fish Biology 33: 917-924.

Huntingford, F.A., Metcalfe, N.B., Thorpe, J.E., Graham, W.D. \& Adams, C.E. 1990. Social dominance and body size in Atlantic salmon parr, Salmo salar L. Journal of Fish Biology 36: 877-881.

Hutchinson, G.E. 1957. Population studies - animal ecology and demography: concluding remarks. Cold Spring Harbor Symposia on Quantitative Biology 22: 415-427.

Iwama, G.K., Afonso, L.O.B. \& Vijayan, M.M. 2004. Stress in fish. AquaNet workshop on fish welfare. British Columbia: Campbell River, 9 pp.

Jones, M.L. \& Stanfield, L.W. 1993. Effects of exotic juvenile salmonines on growth and survival of juvenile Atlantic salmon (Salmo salar) in Lake Ontario tributary. In: Gibson, R.J. \& Cutting, R.E., eds. Production of juvenile Atlantic salmon, Salmo salar, in natural waters. Canadian Special Publication of the Journal of Fisheries and Aquatic Sciences 118. Ottawa: National Research Council Canada, pp. 71-79.

Jonsson, E., Johnsson, J.I. \& Bjornsson, B.T. 1998. Growth hormone increases aggressive behavior in juvenile rainbow trout. Hormones and Behavior 33: 9-15.

Kalleberg, H. 1958. Observations in a small stream tank of territoriality and competition in juvenile salmon and trout (Salmo salar L. and S. trutta L.). Report of the Institute of Freshwater Research Drottningholm 39: 55-98.

Keenleyside, M.H.A. \& Yamamoto, F.T. 1962. Territorial behaviour of juvenile Atlantic salmon (Salmo salar L.). Behaviour 19: 139-169.

King, T.L., Verspoor, E., Spidle, A.P., Gross, R., Phillips, R.B., Koljonen, M.-L., Sanchez, J.A. \& Morrison, C.L. 2007. Biodiversity and population structure. In: Verspoor, E., Stradmeyer, L. \& Nielsen, J.L., eds. The Atlantic salmon: genetics, conservation and management. Oxford: Blackwell Publishing, pp. 117-166.

Korsu, K., Huusko, A. \& Muotka, T. 2010. Impacts of invasive stream salmonids on native fish: using meta-analysis to summarize four decades of research. Boreal Environment Research 15: 491-500.

Lynch, M. \& Walsh, B. 1998. Genetics and analysis of quantitative traits. Sunderland: Sinauer Associates, 980 pp.

Marsden, J.E., Chipman, B.D., Pientka, B., Schoch, W.F. \& Young, B.A. 2010. Strategic plan for Lake Champlain fisheries. Great Lakes Fisheries Commission Miscellaneous Publication 2010-03. Ann Arbor: Great Lakes Fishery Commission. 54 pp.

Maule, A.G., Schreck, C.B. \& Kaattari, S.L. 1987. Changes in the immune system of coho salmon (Oncorhynchus kisutch) during the parr-to-smolt transformation and after implantation of cortisol. Canadian Journal of Fisheries and Aquatic Sciences 44: 161-166. 


\section{Houde et al.}

McDowall, R.M. 2006. Crying wolf, crying foul, or crying shame: alien salmonids and a biodiversity crisis in the southern cool-temperate galaxioid fishes? Reviews in Fish Biology and Fisheries 16: 233-422.

Meffe, G.K. 1995. Genetic and ecological guidelines for species reintroduction programs: application to Great Lakes fishes. Journal of Great Lakes Research 21: 3-9.

Metcalfe, N.B. 1986. Intraspecific variation in competitive ability and food intake in salmonids: consequences for budgets and growth rates. Journal of Fish Biology 28: 525531.

Metcalfe, N.B., Taylor, A.C. \& Thorpe, J.E. 1995. Metabolic rate, social status and life-history strategies in Atlantic salmon. Animal Behaviour 49: 431-436.

Mommsen, T.P., Vijayan, M.M. \& Moon, T.W. 1999. Cortisol in teleosts: dynamics, mechanisms of action, and metabolic regulation. Reviews in Fish Biology and Fisheries 9: 211268.

Morantz, D.L., Sweeney, R.K., Shirvell, C.S. \& Longard, D.A. 1987. Selection of microhabitat in summer by juvenile Atlantic salmon (Salmo salar). Canadian Journal of Fisheries and Aquatic Sciences 44: 120-129.

Nelson, R.J. 2011. An introduction to behavioral endocrinology. 4th edn. Sunderland: Sinauer Associates, 425 pp.

Oliveira, R.F., Silva, A. \& Canário, A.V.M. 2009. Why do winners keep winning? Androgen mediation of winner but not loser effects in cichlid fish. Proceedings of the Royal Society of London B 276: 2249-2256.

Olsen, E.M. \& Vøllestad, L.A. 2001. An evaluation of visible implant elastomer for marking age-0 brown trout. North American Journal of Fisheries Management 21: 967970.

[OMNR] Ontario Ministry of Natural Resources 2005. Stocks catalogue. Peterborough: Fish and Wildlife Branch, Ontario Ministry of Natural Resources, $182 \mathrm{pp}$.

Øverli, Ø., Harris, C.A. \& Winberg, S. 1999. Short-term effects of fights for social dominance and the establishment of dominant-subordinate relationships on brain monoamines and cortisol in rainbow trout. Brain Behavior and Evolution 54: 263-275.

Øverli, Ø., Korzan, W.J., Höglund, E., Winberg, S., Bollig, H., Watt, M., Forster, G.L., Barton, B.A., Øverli, E., Renner, K.J. \& Summers, C.H. 2004. Stress coping style predicts aggression and social dominance in rainbow trout. Hormones and Behavior 45: 235-241.

Pickering, A.D. \& Pottinger, T.G. 1989. Stress responses and disease resistance in salmonid fish: effects of chronic elevation of plasma cortisol. Fish Physiology and Biochemistry 7: 253-258.

Rosenau, M.L. \& McPhail, J.D. 1987. Inherited differences in agonistic behavior between two populations of coho salmon. Transactions of the American Fisheries Society 116: 646654.

Ruzzante, D.E. 1994. Domestication effects on aggressive and schooling behaviour in fish. Aquaculture 120: 1-24.

Scott, R.J., Poos, M.S., Noakes, D.L.G. \& Beamish, F.W.H. 2005. Effects of exotic salmonids on juvenile Atlantic salmon behaviour. Ecology of Freshwater Fish 14: 283-288.

Sloman, K.A., Metcalfe, N.B., Taylor, A.C. \& Gilmour, K.M. 2001. Plasma cortisol concentrations before and after social stress in rainbow trout and brown trout. Physiological and Biochemical Zoology 74: 383-389.

Smith, A.P. \& Quin, D.G. 1996. Patterns and causes of extinction and decline in Australian conilurine rodents. Biological Conservation 77: 243-267.

Stanfield, L.W. \& Jones, M.L. 2003. Factors influencing rearing success of Atlantic salmon stocked as fry and parr in Lake Ontario tributaries. North American Journal of Fisheries Management 23: 1175-1183.

Sumpter, J.P., Dye, H.M. \& Benfey, T.J. 1986. The effects of stress on plasma ACTH, $\alpha-\mathrm{MSH}$, and cortisol levels in salmonid fishes. General and Comparative Endocrinology 62: 377-385.

Swain, D.P. \& Holtby, L.B. 1989. Differences in morphology and behavior between juvenile coho salmon (Oncorhynchus kisutch) rearing in a lake and in its tributary stream. Canadian Journal of Fisheries and Aquatic Sciences 46: 1406-1414.

Symons, P.E.K. 1968. Increase in aggression and in the strength of the social hierarchy among juvenile Atlantic salmon deprived of food. Journal Fisheries of the Research Board of Canada 25: 2387-2401.

Van der Kraak, G.J., Sorensen, P.W., Stacey, N.E. \& Dulka, J.G. 1989. Periovulatory female goldfish release three potential pheromones: 17 $\alpha, 20 \beta$-Dihydroxyprogesterone, $17 \alpha, 20 \beta$-dihydroxyprogesterone glucuronide, and 17 $\alpha$-hydroxyprogesterone. General and Comparative Endocrinology 73: 452-457.

Van Zwol, J.A., Neff, B.D. \& Wilson, C.C. 2012a. The influence of non-native salmonids on circulating hormone concentrations in juvenile Atlantic salmon. Animal Behaviour 83: 119-129.

Van Zwol, J.A., Neff, B.D. \& Wilson, C.C. 2012b. The effect of nonnative salmonids on social dominance and growth of juvenile Atlantic salmon. Transactions of the American Fisheries Society 141: 907-918.

Vehanen, T. 2006. Intra- and interspecific competition in hatchery landlocked salmon and brown trout in semi-natural streams. Environmental Biology of Fishes 76: 255-264.

Volpe, J.P., Anholt, B.R. \& Glickman, B.W. 2001. Competition among juvenile Atlantic salmon (Salmo salar) and steelhead (Oncorhynchus mykiss): relevance to invasion potential in British Columbia. Canadian Journal of Fisheries and Aquatic Sciences 58: 197-207.

Wendelaar Bonga, S.E. 1997. The stress response in fish. Physiological Reviews 77: 591-625.

Wingfield, J.C., Hegner, R.E., Dufty, A.M. Jr \& Ball, G.F. 1990. The 'challenge hypothesis': theoretical implications for patterns of testosterone secretion, mating systems, and breeding strategies. American Naturalist 136: 829-846.

\section{Supporting Information}

Additional Supporting Information may be found in the online version of this article:

Appendix S1. Design details for on the semi-natural stream tanks.

Appendix S2. Semi-natural stream tank experimental design examining the effects of competition using LaHave and Sebago Atlantic salmon (Salmo 
Non-native salmonid competition with Atlantic salmon

salar) and four non-native salmonid species (brown trout - S. trutta, rainbow trout - Oncorhynchus mykiss, Chinook salmon - O. tshawytscha, and coho salmon - O. kisutch).

Appendix S3. Numbers of LaHave and Sebago Atlantic salmon (Salmo salar) and four non-native salmonid species (brown trout $-S$. trutta, rainbow trout - Oncorhynchus mykiss, Chinook salmon $O$. tshawytscha, and coho salmon - O. kisutch) in the semi-natural stream tanks at 3 and 10 months.

Appendix S4. Summary of trait differences between treatments relative to the control for LaHave and Sebago Atlantic salmon (Salmo salar). 